\title{
Coping with Covid - 19 in New Normal - Influence of Management Measures of Employee Wellbeing in Hotels
}

\author{
Navanita Naskar ${ }^{*}$ and Nita Thomas ${ }^{\dagger}$
}

\begin{abstract}
The hospitality industry is a place where there is high interaction among guests and employees. The employee should comply with protective measures against COVID19. The management team should develop standards for employee wellbeing in hotels. This study was conducted to understand the influence of the management measures on the well-being of employees during COVID-19. Further, it aims to understand any relationship between the independent and dependent variables. Additionally, it also tries to find any significant difference between the age groups and gender categories. SPSS was used as a tool for analysis. 301 responses were collected for a nonparametric correlations test. Mann Whitney U test, univariate analysis of age variance was done to find if there is a significant difference between the variables and age group. The results show a high correlation between the working condition measures and employee wellbeing. This resulted in the acceptance of the null hypothesis.
\end{abstract}

Keywords: Covid-19, employee wellbeing, Hotel, Management measures

\footnotetext{
* Department of Hotel Management, CHRIST (Deemed to be University), Central Campus, Bangalore, Karnataka, India; navanita.naskar@bhm.christuniversity.in

† Department of Hotel Management, CHRIST (Deemed to be University), Central Campus, Bangalore, Karnataka, India; nita.thomas@christuniversity.in
} 


\section{Introduction}

World Health Organization (WHO) announced the COVID-19 outbreak as a Pandemic on March 11, 2020. Due to a worldwide lockdown, many hotels had to shut down operations entirely, and few were open for partial operation. COVID-19 led to huge business loss and laying off the employees. It has adversely impacted the travel industry and all its segments. The travel and tourism industry experienced its lowest from February 2020, and slowly, the occupancy level started dropping from 100 to 0 . Some of the hotels were turned into quarantine centres for the COVID -19 affected patients. As the lockdown extended, many hotels started laying off their employees.

Experts suggested and the article reported possible job loss across tourism and allied industries. There was a potential job loss in the Indian tourism and hospitality industry. According to KPMG, a financial service and business advisory firm, around 36 million job losses (that is $70 \%$ of the total workforce) on April 01 (Chaitanya, 2020).

Hotels are the most stressful places to work. It requires both physical and mental wellbeing. The topmost priority for the management is taking measures to support employees' physical and psychological health during unprecedented situations like a pandemic. There should be specific measures in the workplaces to help ensure the safety of employees. The organisation should provide resources to help cope with the stress levels and maintain employees wellbeing. The current research project focuses on the following questions: What are the measures adopted by the management in the hotels for the employees wellbeing? What are the measures that can be improved for the well-being of employees? Do they consider the factors like stress, anxiety, the mental imbalance that can reduce the employees' productivity? Do the hotels follow these measures strictly? Is the management open to honest review and changing the measure that suits the best for the employees? Is the hotel management providing funds for those who are laid off? Will there be rehiring? What are the measures taken for health and safety? Are there any monetary or nonmonetary benefits are provided? 
The hotel industry is taking several safety measures to keep the guests safe. The government of India also issued regulations that hotels had to comply with, while reopening the property. Primary focus was given to guest safety and precautionary measures. Hotels are partnering with significant companies who are hiring short term employees to place those who have lost jobs.

The research is to find out measures that the management has taken for the beneficiary of employees and their wellbeing. The pandemic situation has taken a physical and psychological toll on everybody from losing the jobs to unemployment. Significantly, salary deductions has also affected the livelihood of many employees. It is most crucial to take care of the employees health and safety as much as the guests. As the hotels take guests from different locations, they act as hotspots of disease causing virus, and that in turn directly puts the health of employees at risk. The current study was conducted on employee wellbeing from lower to top-level who are currently working in the hotel industry.

Hotel housekeepers experience the highest level of health inequalities and in the current COVID-19 pandemic, hotel workers, particularly housekeepers, are at heightened risk of poor outcomes due to job insecurity and exposure risk. Many hotels have considered offering quarantine packages to the affected. These measures have already been in place in hotel chains overseas in Hong Kong and Singapore. Providing quarantine spaces is a smart business move for the hospitality industry, to help cope with the huge financial losses it went through during the pandemic. Quarantine packages will not only be helpful for individuals but also provide some economic relief for the hospitality industry. The most effective level of control is elimination. However, given the many uncertainties associated with COVID-19, the highlighted steps emphasized are administrative controls, Personal Protective Equipment (PPE), and engineering controls. Such measures need to be well-thought-out for all hospitality organizations regardless of being a quarantine site (Rosenberg, 2020, p. 382). A lack of training resources also mean that the staff perceive that their health is not being adequately considered by their employers and feel an increased risk of disease exposure. There are other challenges faced by many frontline workers, such as supermarket workers or 
delivery boys. They are not considered even though they are front line workers and provide critical service to the public (Williamson et al., 2020, p. 317).

Governments reactions to COVID-19 have differed gigantically from one locale to another and are dependent upon quick change. On certain occasions, government has been unavailable to offer help to organizations and a portion of the people affected by the outcomes of COVID-19 and by endeavours to control its spread. Such reactions incorporate duty and monetary help for organisations, wage endowments, and changes in the standards overseeing wiped out pay privileges to empower labourers to selfdisengage in case of ailment instead of staying in the labour force (Baum et al., 2020, p. 2827). Workers are at higher risk of exposure despite the use of protective measures or equipment, contact with patients is possible. This group includes essential workers such as healthcare workers (physicians, nurses, hospital lab technicians, and other healthcare workers) or public safety workers who have a possible risk of infection. (Rueda-Garrido et al., 2020, p. 304).

\section{Review of Literature}

The present paper uses descriptive data from a tourist accommodation survey to test ryokans. There is compensation based on customer loyalty. To improve the client fulfilment for Japanese vacationer convenience after COVID-19, to restart and reestablish the convenience business on schedule to invite the 2021 Japan Olympic Games and its more extended term improvement later on. Ryokans were chosen as the exploration target since they are more adaptable to lodgings and have more grounded tolerance to manage hazard capacities after Corona virus. The paper explores another massive benefit of the ryokan style of nonstandard lodgings-adaptability. There are three results (1) ryokans are more adaptable to lodgings, have a solid hazard managing abilities, and have received more consideration increasingly from sightseers and backing from the Japanese government; (2) improved techniques for consumer loyalty after COVID-19 were given from IPA; and (3) a unique assessment model of green ryokans was talked about and might be utilized in 
other nations and locales encountering a similar circumstance (Cai et al., 2020, p. 145).

The paper on childcare and remote work during the covid-19 pandemic represented the after effects of a subjective report directed in Italy during the lockdown which pointed towards examining the outcomes of remote work on work-life equilibrium and sexual orientation imbalances in the division of paid and neglected work amidst hetero couples. The paper draws attention from 20 online top to bottom meetings with ten heterosexual couples. The paper features the extension of work over different areas, that deteriorated as the work stretched out. Regardless of whether some talked with men, it was an event to experience more elaborate parenthood. For most of them, a re-examination of their responsibility in paid work is unfathomable. Alternately, mothers are more excited about considering position demands as debatable and see an inescapable obstruction of work in day-to-day life. At the same time, their spouses regularly guarantee that childcare exercises may diminish their profitability. Stretched-out work does not permit the re-definition of the functioning models and does not improve the harmony between serious and fun activities between couples, which is still extensively unequal towards work, with a restricted existence for person exercises. Remote work can increase parental presence with their offspring. However, without a redefinition of dominant models and new organizational systems, remote jobs, whether paying or unpaid, would not increase worklife harmony or result in a more productive workforce. Men and women share caring responsibilities and wish to explore jobs that provide equal opportunities to women. Besides, far-off work does not alter gender standardizing jobs inside homegrown space, even in this uncommon limited circumstance. Along these lines, it repeats and simultaneously fuels sexual orientation disparities among ladies attempting to adjust their twofold job. (Cannito \& Scavarda, 2020, p. 809)

Some studies on Mental wellbeing and work engagement investigate what COVID-19 means for mature age workers' psychological wellbeing by presenting difficulties to mental flexibility which influence their work commitment. The information was gathered from three nations, China, Pakistan, and 
the UK, through eighteen semi-organized interviews. Three subtopics come under the centre topic of "mental difficulties": "intellectual challenges," "actual difficulties," and "social difficulties." Also, "singular versatility" and "bunch flexibility" arose under the centre subject of "mental versatility." The research adds to the body of information by emphasizing the problems faced by elderly workers at the risk of the virus, which negatively impact their job commitment. The research also looks at intervention mechanisms used by these people that directly impact their mental health. Also, the study introduced a methodological model for testing in the field. The outcomes showed that mature age workers psychological wellness without having any unexpected issues was likewise influenced during the Pandemic, consequently bringing about low work commitment. The information was gathered from three nations, particularly China, Pakistan, and the UK. Moreover, information was gathered through telephonic meetings, so a few parts of the investigation may be left alone, which must be conceivable through vis-à-vis association. By the past writing, this examination shows that challenges investigated and identified with COVID-19 can essentially impact maturing representatives psychological prosperity. The investigation likewise urges managers to comprehend the limits of maturing workers and create adaptable approaches that can affect work commitment. The examination presents a novel approach adding to the information whole of COVID-19 effect on prosperity and work commitment of sound, however aged representatives (Abbas \& Zhiqiang, 2020, p. 361).

Due to the effect of the public lockdown during Covid-19, a few associations had to pick remote working, which presented a few difficulties as well as freedom to the representatives and their businesses. The justification for conveying this observational investigation is that the subject is new and work-related pressure exists all over; a lack of examination has been accounted for such studies. This meticulous investigation reports the after-effects of the impact of work-related pressure and distant chipping away of representatives mental prosperity in the Information Technology industry. The different relapse of investigation results uncovered independent variables like a friend, job uncertainty, association 
environment, and occupation fulfilment which are fundamentally affecting the mental prosperity of the workers in the Information Technology Industry. There are minor measurably huge bunch of sex and age contrasts that influence workers mental prosperity, as noticed. The investigation infers that the distant working alternatives should be worked out by the business at every possible opportunity, to decrease the pressure and improve the mental prosperity of workers. The impact of seven autonomous words related pressure causing factors including responsibility, peer, physiological elements, job uncertainty, association environment, mental factors and occupation fulfilment, and a free factor, far off working, on the reliant factor of representatives mental prosperity Information Innovation industry was also estimated. The mental prosperity was estimated with five subscales - climate authority, positive development, positive relations, self-acknowledgement and self-sufficiency. The variables were estimated utilizing an overview instrument, an organized undisguised poll, while subordinate components were estimated with an abbreviated form of 18 thing Ryff's scale. The deductions of the result were made utilizing suitable measurable methods (Prasad et al., 2020, p. 1).

Dread of COVID-19 showed reasonable social changes in the populace. It persuades individuals to follow the general wellbeing guidelines to decrease the opportunity to spread the infection, which prompts further mental results. It fundamentally affects the travel industry because of movement limitations. WHO predicts that global traveller appearances will be diminished remarkably worldwide in 2020. COVID-19 causes exceptional financial issues for the hospitality industry, facing the diminished visitor numbers and expanded expense of security and preventive gauges. The vulnerability will go on until the first round of fruitful immunisation. The mental outcomes of delayed lockdown and social confinement lead to the expanded requirement for opportunity throughout the mid-year: numerous individuals try not to need to drop their past unique plans. Occasional lodging labourers hang tight to finish the movement limitations and the uplifting news from their manager to travel and begin working. Then again, various people are against the launch and scared of the "second wave" of the disease and backing further. Surprisingly, 
stricter security measurers during the Covid pandemic influences the understudy portability programs, also the people who have intended to study or work abroad need to confront huge vulnerability. Our exploration means to adjust the Hungarian form of the Fear of COVID-19 Scale and investigate the effect of dread of Covid on the designs to travel, study or work abroad among the $\mathrm{Z}$ and $Y$ ages. The part of keen insight, pressure and web-based media utilization, and the nervousness brought about by the Covid Pandemic will be analysed too. The investigation study clarifies our research plan and actual outcomes as well (Pásztor \& Bak, 2020, p. 178).

The study on hoteliers human resource strategies uncovered the absence of premium as a more significant part of hoteliers seek HR techniques other than laying off their workers because of the shortfall of arrangements created by the local government to support the other HR procedures execution as relates in nations like Australia, Ireland, Japan, United States of America, Canada, and France. The analysis is to survey human asset methodologies received by the hoteliers during the COVID-19 pandemic period in Ghana and measures taken to manage it. Study shows that workers' lay-off is considered the principle Human Resource (HR) system hoteliers in Ghana received during the COVID-19 pandemic period to rescue their organizations in meeting representatives wage bill. However, other HR techniques might have also been received like the incorporating operationalization of a Pandemic setup, reducing representatives working hours, briefly changing workers regular positions over to low maintenance, and repreparing representatives to utilize elective methods for working together. Hence, the research had its primary judgement as surveying the HR methodologies received by hoteliers in Ghana during the time of COVID-19. Different techniques are accessible for hoteliers to browse during the Pandemic. Most firms in the hotel business lean towards laying off their workers as a vital technique to reduce their payable amount to get by during the fierce period and once in a while consider other HR systems as a significant device to help them accomplish their target (Dwomoh \& Luguterah, 2020, p. 34). 
Some viewpoints explicit to the impact of the COVID-19 Pandemic on Romania's working population of intense work speculation. Issues identified with responsibility, exhaustion, work commitment, workaholism, and execution in work were thought of. A review-based examination was directed utilizing a few scales tried in examinations on hefty work venture with the information being prepared in SPSS. The consequences of the examination uncover a negative effect on the parts of heavy work speculation. There was decline in work speculation during the Pandemic for every deliberate perspective, with negative consequences for respondents mentalities towards individual work execution. In light of the examination results, the business climate's primary proposition is to invigorate representatives to accomplish a more elevated level of work commitment, leading to expanded work execution. It can likewise be accomplished by embracing approaches to reduce additional time. The data acquired by the researchers affirm the consequences of other exploration distributed in writing in regards to the negative connection between one workaholism and work commitment and the impact on work execution. The conclusion of the research shows that substantial work speculation can be a decent marvel for both the worker and the business. It is coordinated towards expanding work commitment and improved working time, prompting the worker's expanded work execution. In any case, COVID-19 had a substantial negative effect on working time, even at the level of the individuals who proceeded with their action, enlisting a reduction in work speculation (Tecau et al., 2020, p. 1049).

The primary objective of the article on cases on hotel performance is to depict the transient effects of complex new cases and passing of the COVID-19 infection on lodgings exhibitions in the nine significant Polish metropolitan hotel location: Kraków, Warszawa, Pozna 'n, Wrocław, Gda 'NSK, Lublin, Łód'z, Katowice, and Sopot. The time scope of the examination covers the time frame from January 05, 2020 (the start of the absolute first week when the Coronavirus cases were confirmed) to March 14, 2020 (the Polish government presented the underlying period of lockdown). Different geological settings of the COVID-19 effects are thought of. Techniques were applied to examine the impact of announced 
COVID-19 cases on both inhabitancies and income per accessible room. The outcomes show that the Pandemic's main negative effect on inn exhibitions is affirmed at the European level of the COVID19 flareup. Additionally, the negative impact of public instances of COVID-19 is huge in less internationalized metropolitan objections. Consequently, the lodging business may be recuperated just when issues of the COVID-19 scourge will be tackled at the European level. (Napierała et al., 2020, p. 4697)

The COVID-19 Pandemic has had a broad and extraordinary impact on economies around the world. It has also affected the worldwide population's emotional wellbeing and caused negative psychosocial impacts, prompting mental emergencies. During the pandemic, the struggles of isolated inn representatives are not just the expanded workloads made by working on isolated lodging but also high mental pressure related to work weaknesses, a hazard of opening up and exposing themselves and their loved ones up to viruses. This examination endeavours to investigate COVID-19related sorrow, uneasiness, and stress among isolated lodging representatives in China. The psychological wellness of isolated lodging workers, who have confronted unprecedented changes, is vital. At the same time, they give neighbourliness and care to medical care labourers and isolate visitors during critical isolation periods. The discoveries uncover that most isolated hospitality workers in China have moderate-to-extreme symptoms of wretchedness and uneasiness. This investigation shows that the pervasiveness of sorrow and uneasiness in an isolated hospitality representative is more noteworthy than past investigations have found in any other medical services labourers in the world. It may be since isolating the lodging representatives, as a rule, have a lower pay and instructive foundation than medical care workers, just as an absence of information toward the Pandemic (Teng et al., 2020, p. 2750). Ethiopia has taken strict preventive measures against COVID-19 to control its spread, secure residents, and guarantee prosperity. Workers adherence to preventive measures is impacted by their insight, sincerity, advantage, obstacles and self adequacy. Along these lines, this examination explored the indicators of COVID-19 avoidance work on utilizing the Health 
Belief Model among representatives in Addis Ababa, Ethiopia, 2020.

From mid-March to the furthest limit of May 2020, many Italians had to telecommute on account of the Italian government's lockdown arrangements to contain the COVID-19 pestilence. Subsequently, numerous representatives needed to, out of nowhere, change to far off work, encountering inconveniences and searching for openings. Social confinement from associates and the working environment addresses a run-of-the-mill part of remote work, which expanded essentially during the public authority's social repression. This examination explores social disengagement connections regarding pressure, seen distant work profitability and far off work fulfilment, proposing the consecutive intercession of stress and seen distant work profitability, and the directing job of worrying about the new Covid. An online overview was conducted, and the reactions of 265 workers appeared the dangerous part of social seclusion in pressure, which prompts diminished apparent far off work efficiency that, thus, is identified with distant fulfilment. Moreover, the outcomes propose that worry about the infection directs the connections between friendly detachment and distant work fulfilment, from one side, and distant apparent efficiency and remote work fulfilment from the other. This last outcome proposes that social seclusion's indirect consecutive impact on distant work fulfilment is contingent on worry about the infection. A few ends are drawn to help chiefs and HR officials make decisions to all the more likely deal with representatives work during the wellbeing crisis (Toscano \& Zappalà, 2020, p. 9804).

The study titled "Employee mental wellbeing amidst Covid-19: Major stressors and distress" attempts to fill the hole and endeavour to investigate the local working area and business's natural stressors. Besides, the investigation too clarifies the results of stressors, which are as trouble, assesses the hierarchical endeavours from the point of view of human asset the executives, limiting the glitches confronted by workers. The association of workers ought to be a significant worry for each association. To keep the workers spirit high, and to keep up the degree of profitability, is a very difficult task for each business. As 
representatives are battling their mental status, workers psychological wellness should involve worry for each association. The examination is a pioneer in the effect of Covid, which uncovers the, generally speaking, effect of the Covid on humans, especially to the work environment, which has quickly held the whole globe. This paper investigates the different peripherals of nervousness, stress, and disillusionment among India's working labour, challenging medical examinations relating to emotional wellness. The new examinations and patterns appear to be disregarding the mental misfortune and issues associated with the Pandemic. This paper is a powerful device for associations, human asset chiefs, and concerned strategy producers to address the specialists' psychological wellness. Since COVID-19 has deadened labourers', existence taking all things together with the circles, this examination could demonstrate a distinct advantage in propelling and upgrading labourers' spirits (Saxena \& Gautam, 2020, p. 2552).

There is convincing proof that representative-focused HRM rehearses firmly sway worker prosperity. This paper incorporates knowledge from an HRM structure for prosperity utilizing a task requests assets model. The paper recognizes subjects that affirm and broaden existing speculations and models of prosperity. The discoveries are significant for strategy creators by offering direction for overseeing individuals adequately during difficult stretches. All lodgings had eliminated all motivations and advantages. Everything except three hotels had cut around $50-60 \%$ of all representatives compensation. One hotel had not cut or reported any compensation cuts. Two hotels had not cut workers compensation at the most minimal level, like housekeeping and janitors. One hotel had begun the act of transcribing letters from top management to bring down level representatives as a badge of appreciation (Agarwal, 2021, p. 102765).

Another study focused on the worker's working conditions and supporting safety, health, and wellbeing during the COVID- 19. The result focuses on controlling the infection and supportive environment for the worker with daily challenges, psychological demand, efficient system with legal guidelines and framework. Coronavirus has brought about extreme challenges to work environment safety and wellbeing for employees in an 
organization, including healthcare employees, delivery services, administrations, distribution centres. Front line workers need assurance, precise information, and a supportive work environment with a steadfast spotlight on robust disease control. The study's methodology examined the workplace environment that is steadily affected by the virus. The primary issue was finding a suitable place where the workers will be safe active against the novel Coronavirus. The organization ensures the well-being of employees and developed norms and guidelines for health and safety. These guidelines were used as a theoretical study in the article. These guidelines provided an SOP and specified health and safety issues, control over the disease, and measures for psychological needs in the workplace. The result that was driven was six factors that pointed to the employee's working condition and steady control and providing a supportive environment for the mental health needs. Management needs to approach employees and be more supportive and help identify the challenges and suggestions to solve, utilizing hard work and solutions to form a better system and efficiency. Communication and action in the workplace to be developed by the top management, prevention measures to be followed strictly provided by the government and the guidelines provided, action plan to be made accordingly in the future, utilizing information to manage activities and assess progress (Dennerlein et al., 2020, p. 693).

A research study is distinct about the health concerns, the economic crisis that hit the industries hard worldwide due to the COVID-19 pandemic. Raising the novel corona virus's concern led to many workers working remotely and working from home to keep up the service business. This working remotely limited the resources, communication, and leadership skills and it widened the teamwork gap. The article's focal point is that the limited resources and virtual platforms affect how effective leadership and employee performance are brought together. The author used input process outcomes to draw for examining the effectiveness of leadership and service employees work performance. The examination was conducted in the middle of tension in the situation group. Furthermore, it explores the effect of technology that was provided on the service employees. The study's sample size was 206 service 
employees participating who had to switch to a virtual platform due to the present situation. According to the author, the result shows task and relationship-oriented behaviour to maintain the virtual platform's work performance during a pandemic. Other results also indicate the effect of individual job autonomy of service employees and teamwork. Work performance was not impacted due to the tension. The provided guidance that was developed effectively led to the crisis when employees came up with the new typical virtual environment. This empirical study showed the leadership effect in service employees work performance in the organization with technological-driven tasks and a new virtual world during a pandemic (Bartsch et al., 2020, p. 82).

The paper related to social distancing measure's impact on the service employees wellbeing during COVID-19 implicated and investigated social distancing practices on employee wellbeing. The pandemic crisis hit the livelihood of several lives. The service industry and other businesses are either completely shut down or went into hibernation. The norms of social distancing measures are rising because of the concerns of the employee's wellbeing, for those businesses which for on continuity and who are resuming back from the hibernation. The study was designed to draw data and reports from the industry and associate it with the theoretical concepts to a structure in the research and to provide a point of understanding about the Pandemic's impact on the employees wellbeing. Tuzovic's research examines the impact of social distancing practices on the well-being of employees. The author suggested different business concepts as a response to social distancing measures service hibernation and continuity. The author tried to bridge the theoretical understanding of the two domains, the impact of social distance and measures related to it. The author described different dimensions of the wellbeing of the employees, like the physical, mental, social, and financial wellbeing. Also, designed themes to understand the short-term and long-term orientation of framework required to approach as the questions are complicated and involve different management levels. This paper requires different approaches to investigate or test various factors to understand employee wellbeing (Tuzovic \& Kabadayi, 2018, p. 154). 
Discussion regarding the COVID-19 has dominated the research study recently due to the global crisis. COVID-19 in the hospitality and tourism industry through human rights interpretation. This paper's discussion considers some of the human rights during the new standard return in post COVID. To describe the current situation, it is designed based on current events and interpretations of the human rights lens. Some information was misinterpreted like border closing, decline of travel, close of tourist attraction and facilities. They were considering the cancellation of consumer protection rights in the hotel industry. Return of people to their home country, an emergency place for residing and penalties for non-compliance, restriction for those visiting their friend and family, guest staying back at the hotel due to travel restriction, abuse of minorities, boycotting their business was put in the light. The article covers the silver lining of individual rights to travel due to COVID-19 and its impact, but there was a positive side to the impact. Human trafficking was reduced, reducing child sex tourism, human rights, tourism, and the environment. A few questions unanswered in this study were the right to mobility, travel, and the needs of the tourist. The paper needs to be addressed with an ongoing scenario and post COVID-19 situation. The study's question can validate if the hospitality industry is ready to participate in this kind of study (Baum \& Hai, 2020, p. 2399).

The effects of Covid-19 are generally alarming for low-income families who are in the situation; they must cope with losses and find alternative income sources for their livelihood. With no social security, most of them acquire minimal wage that only meets their basic needs-have with no intention to secure their earnings. These workers contribute to quite a large population of India, and they also play a vital part in society. These employees were left unemployed in the country due to lockdown. Many workers are forced to be left unemployed in India because of the lockdown and waiting for the lockdown lift to get back to their jobs. Millions of workers have gone back to their hometowns and numerous more hope that the lockdown will be lifted. The danger is more significant for the individuals working in infected and exposed to 
disease-prone areas - the individuals who don't have contracts or those whose contract has not been completed. From one perspective, lockdowns and social distancing measures have led to job losses, and wages cut subsequently, and others did not even get their pay. To survive in this extreme many left the cities with no transportation frameworks and flexible chains to return home. With no guaranteeing food availability and control over the disease, no government support system in the initial days (Khanna, 2020, p. 184).

COVID-19 pandemic's present scenario has brought a vast, unforeseen, and unexpected disturbance to billions of representatives worldwide. Industries and workers have been compelled to change their routine operations overnight. It created special requests to settle critical conditions, and managers are carry the burden on their to find appropriate solutions. The new normal resulted from the COVID-19 is that many professionals have either lost their job or have taken up work from home careers. Accordingly, associations have received innovation-driven arrangements. Managers try to communicate with workers time to time for gathering information, keep track of related issues, and adapt to technological-driven solutions to contact employees. The virtual world helped to bridge the gap and bringing the business back. The author collected samples from the University who which changed or updated their guidelines for staff. The study showed that the staffs are not aware of the facts, and management was not persistent in informing them about the changes. The team relied on the news and articles published online or those broadcasted on TV. This study helped to understand the need to remove communication gap through technology that would have solved the problem (Sanders et al., 2020, p. 291).

COVID-19 disrupted the psychological wellness of individuals all around the globe- The aim behind this study is to distinguish 'Fear of COVID-19' and future workforces career anxiety. The author used three different scales to measure the fear of COVID that could trigger depression, and anxiety was related to this study. A structured questionnaire was made, and survey information was collected. The experiment aftereffect of the result uncovered that, because of COVID-19 fear, the employees were anxious about the 
work and work environment. The fear of COVID -19 caused depression. This fear also leads to future anxiety and emotional breakdown among the workers. The topic was to identify the needs to help and support the employees. This implies that the flare-up of 'Fear of COVID-19' individuals are getting discouraged and are on the edge about their future profession, making a drawn-out negative impact on human brain research. These findings bought from the study will be an essential instrument for the framework (Mahmud et al., 2020, p. 2076402093548).

India faces a philanthropic calamity of exceptional proportions. $90 \%$ of the Indian workforce is utilized in the disorderly area; uncounted millions work in metropolitan cities in excellent ways from country homes. At the point when the Government of India (GOI) reported the abrupt 'lockdown' in March to encompass the spread of the Pandemic, the migrant workers suffered from lack of endurance in emergency, pay misfortune, hunger, dejection, and oppression from specialists policing control and frightful networks keeping up social distancing. In this circumstance, the article examines how the COVID-19 Pandemic emphasized neediness, casualness, and imbalance. The article inspects the nature, extent of existing social arrangement, planned under changing political systems and a fluctuating monetary atmosphere, to ensure this weak gathering and relieve separation, segregation, and dejection as of now and in the future. The crisis was bought in the policy for the centred migrants worker and their immigration. It is connected to social media surrounding the panic about migrants and pandemics. The tragedy showed that the migrant workers are going through the toughest time- Every situation is turning against the worker during the Pandemic (Sengupta \& Jha, 2020, p. 166).

\section{Research Methodology}

The objective of the study is to understand the influence of the management measure on employee wellbeing in the hotel during COVID-19. The area of the study covers employees in the hotel industry. The study is quantitative and employs a descriptive research method. All the employees in the hotel industry across India constituted the population of study. A structured questionnaire was developed to collect primary data. Descriptive 
statistics and Spearman correlation test is applied to analyse the data. IBM SPSS Statistics Version 27 was used as the statistical application for the accurate and reliable analysis of the data to measures measure the relationship between employee wellbeing, working conditions and financial wellness measures during the COVID-19.

\section{Data Analysis and Interpretations}

The analysis of the study is a combination of the management measures that are the Working Condition Measures (WCM) and Financial Wellness Measures (FM); and Employee Wellbeing (WB). The scale measures the relationship between employee wellbeing and working conditions and financial wellness measures during the COVID-19. The WCB, FM, and WB scales are self-assessment tools used to evaluate the various statements provided on the linked scale 1 to 5 . Likert scale is used, where 1 - Strongly Disagree, 2 - Disagree, 3 - Neutral, 4 - Agree, 5 - Strongly Agree. The Working Condition and Financial Wellness Measures increase, and the Employee Wellbeing increases-the impact of the independent measures on employee wellbeing during COVID-19 in the hotel. The wellbeing levels are measured using the same Likert Scale model to assess the various levels of the factors like Financial Wellness Measures and Working Condition Measures in the hotel through the self-assessment statement. The tool accesses the influence of the management measure on the employee wellbeing and how they are related to each other. Thus, the study investigates the influence of management measures on employee wellbeing through IBM SPSS version 27.

Descriptive Statistics

\begin{tabular}{|l|l|l|l|l|l|}
\hline & N & Minimum & Maximum & Mean & $\begin{array}{l}\text { Std. } \\
\text { Deviation }\end{array}$ \\
\hline TWCM & 301 & 8 & 35 & 25.51 & 5.539 \\
\hline TFM & 301 & 5 & 25 & 17.41 & 4.098 \\
\hline TWB & 301 & 14 & 50 & 35.35 & 7.343 \\
\hline $\begin{array}{l}\text { Valid } \\
\text { N(listwise) }\end{array}$ & 301 & & & & \\
\hline
\end{tabular}


Table 1: Descriptive Statistics for Working Condition Measures (TWCM), Financial Wellness Measures (TFM), and Employee Wellbeing (TWB).

\section{Correlations}

\begin{tabular}{|l|l|l|l|l|l|}
\hline \multicolumn{2}{|c|}{} & TFM & TWCM & TWB \\
\hline $\begin{array}{l}\text { Spearman's } \\
\text { rho }\end{array}$ & TFM & $\begin{array}{l}\text { Correlation } \\
\text { Coefficient }\end{array}$ & 1.000 & $.840^{* *}$ & $.889^{* *}$ \\
\hline & & Sig (2-tailed) &. & $<.001$ & $<.001$ \\
\hline & & $\mathrm{N}$ & 301 & 301 & 301 \\
\hline & TWCM & $\begin{array}{l}\text { Correlation } \\
\text { Coefficient }\end{array}$ & $.840^{* *}$ & 1.000 & $.869^{* *}$ \\
\hline & & Sig (2-tailed) & $<.001$ & - & $<.001$ \\
\hline & TWB & $\begin{array}{l}\text { Correlation } \\
\text { Coefficient }\end{array}$ & .801 & 301 & 301 \\
\hline & & Sig (2-tailed) & $<.001$ & $<.069^{* *}$ & 1.000 \\
\hline & & $\mathrm{N}$ & 301 & 301 & - \\
\hline
\end{tabular}

** - Correlations is significant at the 0.01 level (2-tailed)

Table 2: Nonparametric correlations test

A nonparametric test is used in statistical analysis for the distribution, which does not require to meet the needs assumptions to be analysed when the data is not normally distributed. Nonparametric test often serves the parametric test's purpose like T-test or ANOVA that employee for the underlying data, which satisfies specific criteria and assumptions. Table 2 shows the nonparametric test for the total sum of the independent variables like Working Condition measure (TWCM) and dependent variable (TWB). The relationship between Employee Wellbeing and Financial Wellness Measure (TFM) is 0.889 . That means there is a strong correlation between Employee Wellbeing (TWB) and Financial Wellness Measures (TFM). The relationship between Employee Wellbeing (TWB) and Working Condition Measures (TWCM) is 0.869; there is a strong correlation between the variables. 


\section{Summary of Findings}

The current research is conducted to know the influence of the management measures on Working Condition Measures and Financial Wellness Measures on employee wellbeing in the hotel during COVID-19.

The first factor of the variable the Working Condition Measures, where there is a very strong correlation between Working Condition Measures and Employee Wellbeing; the result of significance is 0.889 , indicating the rejection of the alternate hypothesis and accepting the null hypothesis. Since the significance value should be below 0.5 to accept the alternate hypothesis, in the same way, there is a very strong correlation between Financial Wellness Measures and Employee Wellbeing. The result shows the value as 0.889 since it is below 0.5 of the significance levels.

\section{Conclusion}

The study aimed to understand the relationship between the Management Measure and Employee Wellbeing in the hotel during the COVID-19. The study focused on the factors like material provided, commuting, flexible work hours, change in the policies and guidelines, practices, process, job security, funds, financial counselling, bills, health and safety, risk assessment under the Working Condition Measures, Financial Wellness Measures and Employee Wellbeing in the questionnaires and it has been selfscored by the respondents by choosing the scale 1 being the lowest and 5 being the highest. The current research result showed that $\mathrm{s}$ there is a strong correlation between Employee Wellbeing (TWB) and Financial Wellness Measures (TFM). The relationship between Employee Wellbeing (TWB) and Working Condition Measures (TWCM) is 0.869; there is a strong correlation between the variables.

\section{Recommendation}

The research proves the influence of the management measures on employee wellbeing in the Hotel during COVID-19. In the relationship between the variables, there is a strong correlation; 
when one variable increases, the other increases, other factors influence the employee wellbeing other than Working Condition Measures and Financial Wellness Measures in the hotel industry. There is a scope for further study on other factors like revised policies on sick leave, compensation plan, communication process, workload factors, revision on the check-in process of the guest, revised cleaning process, prompting the proper practices, training, and educating can be considered for the study to check the wellbeing of the employees in the hotel during COVID-19. This study opens the scope for further detailed research to understand the significance and relationship between the wellbeing as well as the measures taken by the management in the hotel.

\section{References}

Abbas, S. M., \& Zhiqiang, P. L. (2020). COVID19, mental wellbeing, and work engagement. International Journal of Research in Business and Social Science (2147- 4478), 9(4), 356-365. https://doi.org/10.20525/ijrbs.v9i4.760

Agarwal, P. (2021). Shattered but smiling: Human resource management and the wellbeing of hotel employees during COVID-19. International Journal of Hospitality

Bartsch, S., Weber, E., Büttgen, M., \& Huber, A. (2020). Leadership matters in crisis-induced digital transformation: how to lead service employees effectively during the COVID-19 Pandemic. Journal of Service Management, 32(1), 71-85. https://doi.org/10.1108/josm-05-2020-0160

Baum, T., \& Hai, N. T. T. (2020). Hospitality, tourism, human rights and the impact of COVID-19. International Journal of Contemporary Hospitality Management, 32(7), 2397-2407. https://doi.org/10.1108/ijchm-03-2020-0242

Baum, T., Mooney, S. K., Robinson, R. N., \& Solnet, D. (2020). COVID-19's impact on the hospitality workforce - new crisis or amplification of the norm? International Journal of Contemporary Hospitality Management, 32(9), 2813-2829.

Cai, G., Hong, Y., Xu, L., Gao, W., Wang, K., \& Chi, X. (2020). An Evaluation of Green Ryokans through a Tourism 
Accommodation Survey and Customer-Satisfaction-Related CASBEE-IPA after COVID-19 Pandemic. Sustainability, 13(1), 145. https:// doi.org/10.3390/su13010145

Cannito, M., \& Scavarda, A. (2020). Childcare and Remote Work during the COVID-19 Pandemic. Ideal Worker Model, Parenthood and Gender Inequalities in Italy. Italian Sociological Review, 801-820. https:// doi.org/10.13136/isr.v10i3S.399

Cemazar, S. A. (2020, July 13). Employee Wellbeing in the Workplace: Importance and Future Predictions. Semos Cloud.

Chaitanya Mallapur, IndiaSpend.com. (2020, April 14). India's Covid-19 lockdown may cause 38 million job losses in the travel and tourism industry. Scroll. In.

Chen, Z., Marin, G., Popp, D., \& Vona, F. (2020). Green Stimulus in a Post-pandemic Recovery: The Role of Skills for a Resilient Recovery. Environmental and Resource Economics, 76(4), 901-911. https://doi.org/10.1007/s10640020-00464-7

Dennerlein, J. T., Burke, L., Sabbath, E. L., Williams, J. A. R., Peters, S. E., Wallace, L., Karapanos, M., \& Sorensen, G. (2020). An Integrative Total Worker Health Framework for Keeping Workers Safe and Healthy During the COVID-19 Pandemic. Human Factors: The Journal of the Human Factors and Ergonomics Society, 62(5), 689-696. https://doi.org/10.1177/0018720820932699

Dwomoh, G., \& Luguterah, A. (2020). Hoteliers' human resource strategies for business sustainability during Covid-19 Pandemic in Ghana. A Journal of the Centre for Business \& Economic Research, 14(3), 34. https://doi.org/10.24052/JBRMR/V14IS03/ART-04

Hamdan Mansour, A., Al Shibi, A. N., Khalifeh, A. H., \& Hamdan Mansour, L. A. (2020). Healthcare workers' knowledge and management skills of psychosocial and mental health needs and priorities of individuals with COVID-19. Mental Health 
and Social Inclusion, 24(3), 135-144. https://doi.org/10.1108/mhsi-04-2020-0022

Hennein, R., \& Lowe, S. (2020). A hybrid inductive-abductive analysis of health workers' experiences and wellbeing during the COVID-19 Pandemic in the United States. PLOS ONE, 15(10), e0240646. https://doi.org/10.1371/journal.pone.0240646

ilo.org. (2009, June 15). Workplace wellbeing. Www.Ilo.Org.

Khanna, A. (2020). Impact of Migration of Labour Force due to Global COVID-19 Pandemic with Reference to India. Journal of Health Management, 22(2), 181-191. https://doi.org/10.1177/0972063420935542

Mahmud, M. S., Talukder, M. U., \& Rahman, S. M. (2020). Does 'Fear of COVID-19' trigger future career anxiety? An empirical investigation considering depression from COVID-19 as a mediator. International Journal of Social Psychiatry, 002076402093548. https://doi.org/10.1177/0020764020935488

Napierała, T., Leśniewska-Napierała, K., \& Burski, R. (2020). Impact of Geographic Distribution of COVID-19 Cases on Hotels' Performances: Case of Polish Cities. Sustainability, 12(11), 4697. https://doi.org/10.3390/su12114697

Pásztor, J., \& Bak, G. (2020). Fear of COVID-19 and its impact on holiday planning and working abroad. International Conference on Management, 169-180.

Prasad, K. B. D., Vaidya, R., \& Mangipudi, M. (2020). Effect of occupational stress and remote working on psychological wellbeing of employees: an empirical analysis during covid19 Pandemic concerning information technology industry in Hyderabad. Indian Journal of Commerce $\mathcal{E}$ Management Studies, 2, 1. https://doi.org/10.18843/ijcms/v11i2/01

Rosemberg, M. A. S. (2020). Health and safety considerations for hotel cleaners during Covid-19. Occupational Medicine, 70(5), 382-383. https://doi.org/10.1093/occmed/kqaa053 
Rueda-Garrido, J. C., Vicente-Herrero, M. T., del Campo, M. T., Reinoso-Barbero, L., de la Hoz, R. E., Delclos, G. L., Kales, S. N., \& Fernandez-Montero, A. (2020). Return to work guidelines for the COVID-19 pandemic. Occupational Medicine, 70(5), 300-305. https://doi.org/10.1093/occmed/kqaa099

Sanders, K., Nguyen, P. T., Bouckenooghe, D., Rafferty, A., \& Schwarz, G. (2020). Unraveling the What and How of Organizational Communication to Employees During COVID-19 Pandemic: Adopting an Attributional Lens. The Journal of Applied Behavioral Science, 56(3), 289-293. https://doi.org/10.1177/0021886320937026

Saxena, A., \& Gautam, S. S. (2020). Employee mental wellbeing amidst Covid-19: Major stressors and distress. Journal of Public Affairs, 2552. https://doi.org/10.1002/pa.2552

Sengupta, S., \& Jha, M. K. (2020). Social Policy, COVID-19 and Impoverished Migrants: Challenges and Prospects in Locked Down India. The International Journal of Community and Social Development, 2(2), 152-172. https://doi.org/10.1177/2516602620933715

Sengupta, S., \& Jha, M. K. (2020). Social Policy, COVID-19 and Impoverished Migrants: Challenges and Prospects in Locked Down India. The International Journal of Community and Social Development, 2(2), 152-172.

Spinazzè, A., Cattaneo, A., \& Cavallo, D. M. (2020). COVID-19 Outbreak in Italy: Protecting Worker Health and the Response of the Italian Industrial Hygienists Association. Annals of Work Exposures and Health, 64(6), 559-564. https://doi.org/10.1093/annweh/wxaa044

Tadesse, T., Alemu, T., Amogne, G., \& Endazenaw, G. (2020). Predictors of Coronavirus Disease 2019 (COVID-19) Prevention Practices Using Health Belief Model Among Employees in Addis Ababa, Ethiopia, 2020. Infection and Drug 3751-3761. https://doi.org/10.2147/IDR.S275933 
Tecau, A. S., Constantin, C. P., Lixandroiu, R. C., Chitu, I. B., \& Bratucu, G. (2020). Impact of the COVID-19 Crisis on Heavy Work Investment in Romania. www.Amfiteatrueconomic.Ro, 22(S14), 1049. https://doi.org/10.24818/ea/2020/s14/1049

Toscano, F., \& Zappalà, S. (2020). Social Isolation and Stress as Predictors of Productivity Perception and Remote Work Satisfaction during the COVID-19 Pandemic: The Role of Concern about the Virus in a Moderated Double Mediation. Sustainability, 12(23), 9804. https://doi.org/10.3390/su12239804

Tuzovic, S., \& Kabadayi, S. (2018). The influence of social distancing on employee wellbeing: a conceptual framework and research agenda. Journal of Service Management, 32(2), 145-160. https://doi.org/10.1108/josm-05-2020-0140

Verlinden, N. (2019, November 14). Employee Financial Wellness - All You Need to Know. AIHR Digital. https://www.digitalhrtech.com/employee-financial-wellness/

Williamson, V., Murphy, D., \& Greenberg, N. (2020). COVID-19 and experiences of moral injury in frontline vital workers. Occupational Medicine, 70(5), 317-319. https://doi.org/10.1093/occmed/kqaa052

Working conditions. (2011). Eurofound.

Teng, Y. M., Wu, K. S., Lin, K. L., \& Xu, D. (2020). Mental Health Impact of COVID-19 on Quarantine Hotel Employees in China. Risk Management and Healthcare Policy, Volume 13, 2743-2751. https://doi.org/10.2147/rmhp.s286171 